\title{
Uso de avisos para la explotación y la trata de jóvenes en América Latina*
}

\author{
Norma Constanza Castillo Murillejo** \\ Recibido: 2014-11-23 - Aprobado por pares: 2015-01-05 \\ Enviado a pares: 2014 12-02 - Aceptado: 2015-01-22
}

\section{Resumen}

Este artículo presenta un análisis interpretativo de los resultados de las investigaciones realizadas desde las organizaciones de la sociedad civil, el Estado y la academia en México, Argentina, Bolivia y Colombia, cuyo objeto de estudio han sido los avisos con y sin contenido sexual usados para captar jóvenes para la explotación y la trata. Ilumina respuestas a preguntas básicas desde los modelos funcionalista, estructuralista y crítico de la comunicación social, como: ¿cuál es la relación entre avisos clasificados y trata de personas?, ¿quiénes usan y para qué usan los avisos clasificados con y sin contenido sexual, ¿dónde se originan las investigaciones y qué sentido tiene realizarlas?, ¿qué tipo de metodologías de análisis se utilizan para hacer la interpretación de este fenómeno?, ¿qué resultados han sido obtenidos? y ¿cuáles son los retos que estos nos imponen? Ofrece una caracterización del modus operandi o de la manera como se comporta la captación de jóvenes a través de los medios de comunicación masiva, alternativa e informal en pro de la prevención a víctimas vulnerables. De la misma manera, pone a disposición las estrategias desarrolladas por cada uno de los agentes que actúan en contra de la trata de personas.

Palabras clave: avisos clasificados con contenido sexual, prensa y trata, medios de comunicación y trata de personas, uso de medios

\footnotetext{
Este artículo hace parte de los resultados del proyecto "Estrategias comunicativas audiovisuales para sensibilizar a la población vulnerable sobre la trata de personas del Programa de Comunicación SocialPeriodismo de la Fundación Universitaria Los Libertadores.

* Integrante de la Red Académica Latinoamericana sobre Trata y Tráfico de Personas y la Red Colombiana de Periodistas con Visión de Género. Docente Programa de Comunicación Social-Periodismo de la Fundación Universitaria Los Libertadores.
} 


\title{
Use of Advertising for the Exploitation and Young Sexual Slavery in Latin America
}

\begin{abstract}
This article presents an interpretative analysis of the results of the investigations carried out from the organizations of civil society, the State and the academy in Mexico, Argentina, Bolivia, and Colombia, whose object of study has been notices with and without sexual content used to attract young people to the exploitation and trafficking. It shows answers to basic questions from the functionalist models, and structuralism critic of social communication, such as: What is the relationship between classified ads and sexual slavery? Who use and what is the purpose of using classified ads with and without sexual content? Where is the source of this type of investigations and what is the reason for carrying them out? What type of analysis methodologies are used to make the interpretation of this phenomenon? What results have been obtained? What are the challenges those investigations impose on us? This article offers a characterization of the modus operandi or the way how it behaves capturing youngsters through mass, alternative, and informal media in pro of the prevention to vulnerable victims. In the same way, it makes strategies developed by each of the agents that act against trafficking in persons available.
\end{abstract}

Key words: classified ads with sexual content, press, sexual slavery, mass media and sexual slavery, use of mass media. 

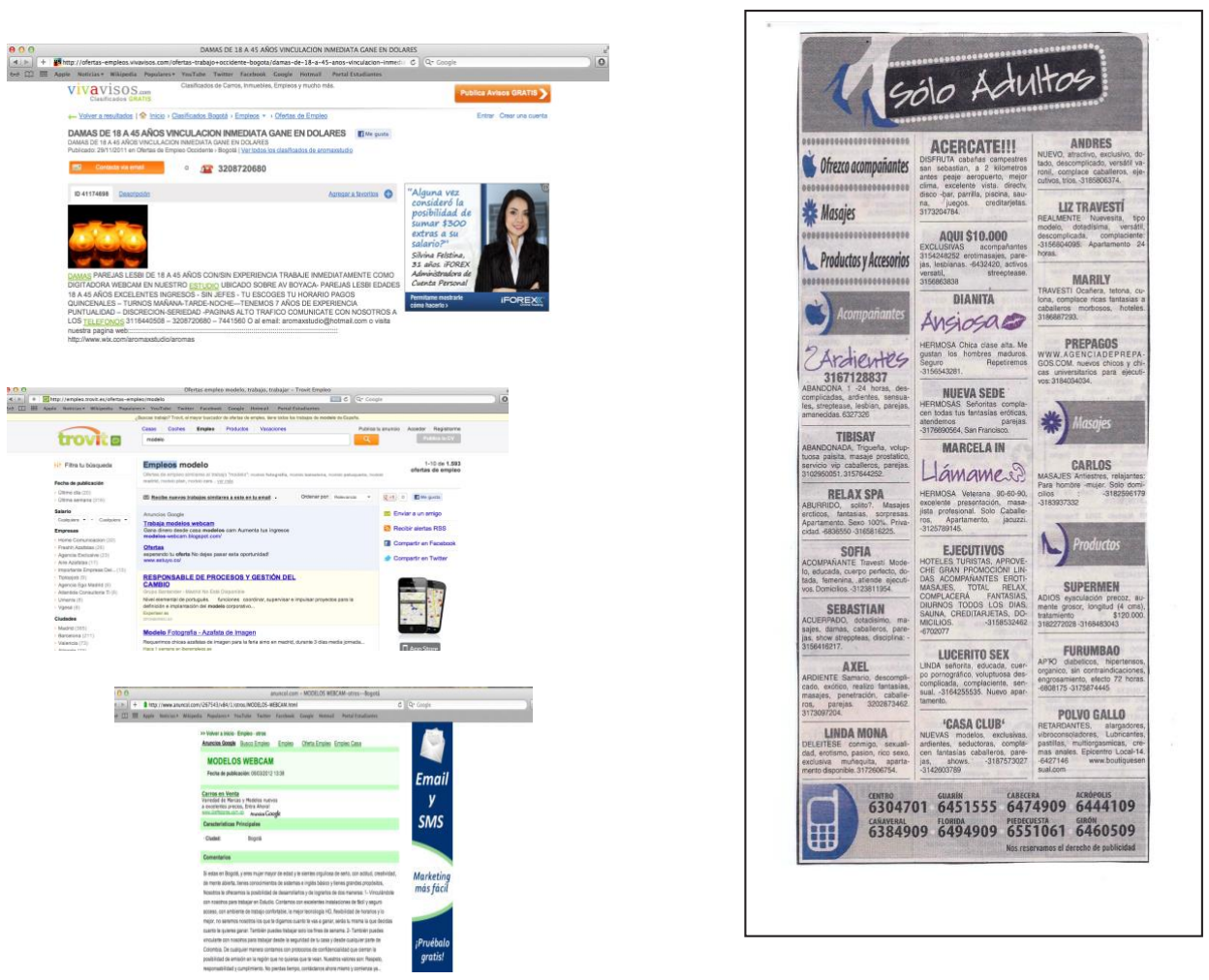

\section{Introducción}

La trata de personas es un delito de lesa humanidad que atenta contra la dignidad y trunca los proyectos de vida. Investigaciones recientes demuestran que sigue "viva" y que los medios de comunicación se encuentran entre los actores que deben movilizarse para combatirla y actuar para transformarla. El reto está planteado, y la convocatoria se abre. Este artículo convoca a los países en mención, léase Argentina, México, Bolivia y Colombia (y a los no mencionados) a sumarse a un frente común que integre: políticas públicas, programas de prevención, apoyo y judicialización para atender tan inconcebible flagelo de la conversión de personas (de las más vulnerables los niños, niñas, adolescentes y mujeres, entre ellos) en objetos comercializables con precio establecido y fluctuante. Después de ofrecer un panorama sobre la situación actual de la explotación y la trata, entraremos a analizar desde las teorías de la comunicación los avances logrados en Latinoamérica sobre el uso de los avisos para captar jóvenes para la explotación y la trata.

En Argentina, "El Colectivo de los Derechos de Infancia señala que la presencia de adolescentes en situación de prostitución en las calles de las ciudades es un fenómeno creciente, de comprobación cotidiana y corrientemente denunciado por los medios de comunicación. Una reciente investigación realizada en Buenos Aires, Posadas y otras ciudades de Misiones; Resistencia y otras localidades del Chaco; la ciudad de Córdoba 
y otras localidades de esa provincia; Neuquén y Puerto Madryn da cuenta de la vida de los adolescentes en situación de prostitución tanto en la calle como encerrados en departamentos privados, hoteles, clubes, saunas y prostíbulos. También informa sobre la existencia de "prostíbulos de lujo" con prostitución juvenil tanto femenina como masculina. (Colectivo de Derechos de Infancia; 2002; p. 9). De una investigación realizada por UNICEF ("La niñez prostituida. Estudio sobre la explotación sexual comercial infantil en la Argentina". UNICEF, octubre, 2001), se pudieron sacar las siguientes conclusiones:

- Ciertas formas de la explotación sexual comercial infantil y juvenil son más visibles, por ejemplo la prostitución callejera pobre y en lugares de fácil acceso.

- Existe un circuito "privado" de prostitución (alimentado por las redes de trata) al cual es casi imposible acceder, tanto por el origen social de quienes son prostituidos como por la notoriedad de los clientes y por la interconexión con otros negocios clandestinos, fundamentalmente tráfico de drogas y la trata de personas.

- También puede hablarse de un nivel más formal: prostíbulos, saunas, discos, proxenetas profesionales y un nivel más informal e inorgánico: padres, familia, novios y proxenetas informales que inician en la prostitución y luego entregan a los niños a los otros.

- Hay coexistencia o convivencia de los niños y adolescentes con mujeres adultas en los espacios de prostitución.

- Las principales tendencias con relación a la edad indican que tanto las mujeres como los varones son iniciados en la prostitución entre los 12 y 13 años, y los 13 y los 16 años, respectivamente. Hay mayor número de niñas y adolescentes mujeres que varones en situación de prostitución, lo que demostrará que el abuso y la explotación están cruzados por aspectos de género. Entre el 40 y el 47 \% de las víctimas de violación sexual son menores de 15 años (CASACIDN; 2002; p. 8)". Esta situación de trata interna ha sido expuesta sin negar que exista la trata transnacional de NNA captadas en Paraguay y Bolivia para esclavitud laboral en Buenos Aires².

En México, se da cuenta de la explotación laboral de menores indocumentados provenientes de Guatemala, Honduras, El Salvador y Nicaragua. También, del alquiler de bebés en jaulas, que posteriormente son usados para mendigar; estos bebés son drogados para que no lloren. Las cifras constatan que entre 2008 y 2013 fueron robados 1000 bebes y 125 mil fueron reportados como desaparecidos y que el $80 \%$ de los niños son hombres entre los 9 y los 18 años que llegan a México en busca de trabajo o que se encontraban en tránsito para los Estados Unidos y fueron abandonados por los Coyotes. Estos niños "encuentran" empleos temporales en la calle como cargadores de equipaje,

\footnotetext{
$1 \quad$ Grima José Manuel. "Trata de personas y derechos humanos". Ponencia central. En: Primer Encuentro Nacional sobre trata de personas. Vínculos para la acción colectiva: sociedad civil, gobierno y academia. Noviembre 6 y 7 de 2012. Bucaramanga, Colombia

2 Segundo Congreso Latinoamericano sobre trata y tráfico de personas. WWW. Tratacongreso2010.org http://www.youtube.com/watch?v=xyz7DTuwatk
} 
mendigos, guías de trámite, robo a transeúntes, prostitución nocturna, ventas ambulantes, pandilleros, en el contrabando, en el narcotráfico o en "sistema hormiga de la droga". Y que a cambio reciben dinero, comida, favores o techo ${ }^{3}$.

En Bolivia, dicen los investigadores que los grupos más vulnerables son los niños y niñas entre 8 a 12 años de edad, los adolescentes entre los 13 y 18 años de edad y los jóvenes entre los 19 y 25 años, con una fuerte incidencia en el género femenino y que los casos más denunciados son la explotación sexual, comercial y laboral. En el año 2007 se conocieron 116 denuncias a escala nacional, y en 2008 fueron 229. Las ciudades donde se registraron más denuncias fueron: El Alto, Santa Cruz, Cochabamba y La Paz. En cuanto a la trata internacional, agregan que un 10 \% de las víctimas fueron traídas de Brasil y Paraguay para la explotación sexual. Y que en La Paz y Santa Cruz se han conocido casos relacionados con menores de edad paraguayas que fueron traídas al país para ser explotadas sexualmente. Así se verifica, una vez más, que la trata de personas y la prostitución de menores forman parte de un solo círculo ${ }^{4}$.

En Colombia, a la fecha ${ }^{5}$, reconocido como país de origen, tránsito y destino se ha caracterizado la trata desde la explotación sexual y laboral, el matrimonio servil y los menores dedicados a las actividades delictivas en el Eje Cafetero y el Cauca. En el Eje Cafetero, las menores son inducidas a la prostitución por sus madres, padres, abuelos o padrastros, quienes consideran que la misma es una oportunidad de trabajo. En el Cauca, son los jefes de comuna o pandilla quienes las convierten en una oportunidad de negocio. Del lado de las actividades delictivas, los varones son utilizados como correos humanos para transportar armas o droga; sus tratantes generan en ellos adicción para mantener el negocio. De este mismo lado, las niñas y las adolescentes son captadas, trasladas y explotadas desde las relaciones afectivas que establecen con los mandos medios. Las mujeres adultas caen en el matrimonio servil porque conocen hombres, a través del chat, que llegan a Colombia como turistas desde otros países. En su mayoría desaparecen y sus familiares, quienes denuncian, las encuentran muertas. Las mujeres indígenas y campesinas caen en la explotación laboral a través de la servidumbre doméstica en Cali (Valle del Cauca) tras aceptar la promesa de recibir a cambio de sus servicios educación y vivienda ${ }^{6}$

3 Cossette Guadarrama Alma (2013). Los Menores Migrantes como Víctimas de la Trata de Personas en la Legislación Mexicana; Dra. Muñoz Cano Skidmore Ma. Dolores y Lic. Granados Cervantes Montcerrat (2013). Trata de niñas y niños con fines de explotación laboral. Ponencia presentada en el III Congreso Latinoamericano sobre trata y tráfico de personas. Globalización trata y acceso a la justicia: articulación de diálogos regionales. http://cei.uniandes.edu.co/index.php/recursos/congreso-trata-2013

4 Bustamante Patricia (2013). Los métodos de la trata de personas en Bolivia. Ponencia presentada en el III Congreso Latinoamericano sobre trata y tráfico de personas. Globalización trata y acceso a la justicia: articulación de diálogos regionales. http://cei.uniandes.edu.co/index.php/recursos/congreso-trata-2013

5 y después de la caracterización realizada por el Estudio Nacional exploratorio descriptivo sobre trata de personas en Colombia realizado por la Escuela de Estudios de Género de la Facultad de Ciencias Humanas de la Universidad Nacional en 2009 en asocio con la Oficina de Naciones Unidas Contra la Droga y el Delito

6 Women's Lin Worldwide (2013). La trata de personas en Colombia: país de origen, tránsito y destino de víctimas de trata transnacional e interna. Ponencia presentada en el III Congreso Latinoamericano sobre trata y tráfico de personas. Globalización trata y acceso a la justicia: articulación de diálogos regionales. http://cei.uniandes.edu.co/index.php/recursos/congreso-trata-2013 


\section{Metodología}

Deriva de la investigación documental y de campo realizada a través del monitoreo temático de este tipo de avisos publicados a través de la prensa electrónica, las páginas web y el espacio público.

\section{Modus operandi de la trata de personas a través de los avisos clasificados}

La relación entre trata de personas y avisos clasificados se establece a partir de lo que ha sido llamado, desde la jurisprudencia, el primer verbo rector que la legislación tipifica al definir la trata de personas: captar7. De acuerdo con la Ley colombiana 985 de 2005 (que sigue a su vez el Protocolo para Prevenir, Reprimir y Sancionar la Trata de Personas, especialmente Mujeres y Niños, conocido como Protocolo de Palermo, acogido por los países latinoamericanos):

[...] el que capte, traslade, acoja o reciba a una persona, dentro del territorio nacional o hacia el exterior, con fines de explotación, incurrirá en prisión de trece (13) a veintitrés (23) años y una multa de ochocientos (800) a mil quinientos (1500) salarios mínimos legales mensuales vigentes... para efectos de este artículo se entenderá por explotación el obtener provecho económico o cualquier otro beneficio para sí o para otra persona, mediante la explotación de la prostitución ajena u otras formas de explotación sexual, los trabajos o servicios forzados, la esclavitud o las prácticas análogas a la esclavitud, la servidumbre, la explotación de la mendicidad ajena, el matrimonio servil, la extracción de órganos, el turismo sexual u otras formas de explotación... el consentimiento dado por la víctima a cualquier forma de explotación definida en este artículo no constituirá causal de exoneración de la responsabilidad penal ${ }^{8}$.

\section{Teoría de redes y trata de personas}

Dicha captación se hace exitosa porque las redes de comunicación humana que se tejen entre quienes hacen uso de los avisos, por un lado (y entre otros), las y los jóvenes que están busca de su primer empleo; y por el otro (y entre otros), las mujeres, los hombres, las y los jóvenes que comercian con el sexo cumplen funciones particulares en completa reciprocidad con el sostenimiento del sistema económico hegemónico, establecido en razón de la subsistencia y el estatus, mediados ambos por la rentabilidad.

Si aplicamos, a manera de ejemplo explicativo, la teoría de las redes sociales ${ }^{9}$ desde su dimensión cualitativa (y no desde la sociométrica o dimensión cuantitativa, como suele hacerse) al uso de los avisos clasificados para la trata de personas en la modalidad de explotación sexual considerada como una situación representativa, es decir, que admite ser generalizada porque se repite en todos y cada uno los países nombrados (respetando

¿Cuál es la relación entre avisos clasificados y trata de personas?

http://www.secretariasenado.gov.co/senado/basedoc/ley/2005/ley_0985_2005.html

White, Douglas R (2005). Teoría de la cohesión circular en el matrimonio y las redes sociales. EMPIRIA. Revista de Metodología de las Ciencias Sociales, núm. 10, julio-diciembre, 205, p.p. 37-69. Facultad de Ciencias Políticas y sociología, Madrid, España. http://www.redalyc.org/pdf/2971/297123998002.pdf 
sus particularidades), podremos no solo identificar los elementos que tejen la red sino concluir por qué se sostiene, a pesar de las sanciones de ley. Entre los elementos que conforman la red se encuentran ${ }^{10}$ :

- Los actores sociales (entendidos como los sujetos interdependientes que se vinculan a través de las redes): los proxenetas, los clientes explotadores, los dueños de los periódicos, los tratantes y quienes "prestan los servicios"

- Los lazos relacionales (definidos como los vínculos que se establecen entre actores y que hacen las veces de vehículo a través del cual se circulan los contenidos): los intermediarios (los proxenetas, los dueños de los periódicos, los tratantes) y los prestadores de servicios llamados "sexoservidores" junto con los consumidores de servicios (los clientes explotadores y los "sexoservidores")

- El contenido (o "materialidad sociológica de la relación", aquello de lo que está hecha el vínculo entre actores sociales y que fluye a través de las relaciones y el intercambio): información y sexo, respectivamente

Y la manera como se organizan los actores y las redes dentro de los grupos:

- En díadas (relación entre dos actores), tríadas (relación entre tres actores) o subgrupos (relación entre más de tres): sexoservidor y cliente, sexoservidores-proxenetas-clientes y sexoservidor-periódico-cliente-proxeneta

Después de este primer análisis resulta evidente que la rentabilidad es aquello que cohesiona la red: todos y cada uno de ellos permanece en la red porque recibe una ganancia monetaria que equivale a la supervivencia y/o el estatus. Y que los medios de comunicación de masas, a pesar de ser auto-concebidos únicamente como "intermediarios", juegan un rol importante en aquello de la rentabilidad. Pues, bien, este caso; el de la rentabilidad (de algunos intermediarios) fue estudiado por Marcos Luis Fuentes y Saúl Arellano en México" ${ }^{11}$.

Estos dos investigadores de la UNAM desarrollaron, en 2012, un análisis exploratorio en los cinco periódicos de mayor circulación en el "Valle de México", los mismos en que mayor cantidad de anuncios de servicios sexuales se publicaban diariamente. Entre los resultados se cuentan: "la magnitud de la presencia de servicios sexuales impresos, el impacto de la suspensión de la publicación de anuncios de servicios sexuales en El Universal y El Gráfico y una cifra de los ingresos brutos que los medios impresos obtienen por la publicación de anuncios de servicios sexuales ${ }^{12 "}$ Bien vale la pena detallar a continuación los principales resultados:

\footnotetext{
10 ¿Quienes usan y para que usan los avisos clasificados con y sin contenido sexual?,

"Fuentes Mario Luis y Arellano Saúl (2012). Los anuncios de servicios sexuales en la prensa escrita mexicana. Un análisis exploratorio en los periódicos El Universal, El Gráfico, Metro, Reforma y La Prensa. CEIDAS. Cátedra extraordinaria Trata de personas. Universidad Autónoma de México. http://investigacion.politicas. unam.mx/catedratrata/?page_ id=591

12 ¿Dónde se originan las investigaciones y qué sentido tiene realizarlas?
} 
- $\quad$ "Los cinco periódicos (El Universal, El Gráfico, La Prensa, Reforma y Metro) publicaron 31,146 anuncios de servicios sexuales. Esto dio un promedio diario aproximado de al menos 70 anuncios diarios. Los periódicos El Universal y El Gráfico publicaron 13,262 anuncios de servicios sexuales, los cuales representarían, en conjunto, ingresos brutos aproximados de $\$ 2,270,000.00$

- La evidencia muestra que lejos de disminuir la cantidad de anuncios, lo que ocurrió fue un "desplazamiento" de prestadores de servicios sexuales de esos medios, hacia los otros que continúan publicando este tipo de publicidad. En efecto, los Periódicos La Prensa, Reforma y Metro, publicaron 17.884 anuncios de servicios sexuales entre el 24 de julio y el 30 de octubre de 2011, los cuales representarían ingresos aproximados de $\$ 1.079 .621 .000$ para cada uno de los medios. De esos anuncios, el $58 \%$ se publicaron entre el 24 de julio y el 20 de septiembre, y el $42 \%$ entre el 21 de septiembre y el 30 de octubre. Es decir, no solo se mantuvo la magnitud en la suma de anuncios, sino que se presenta una tendencia creciente ${ }^{13 " .}$

- Al referirse a las características de quienes prestan los servicios, concluyen que las mujeres representan el 86 \% de la población sexo prestadora; que el 85 \% por ciento de ellas son menores de 30 años, que una de cada tres tiene entre 18 y 20 años y provienen de Jalisco, Colombia y Venezuela.
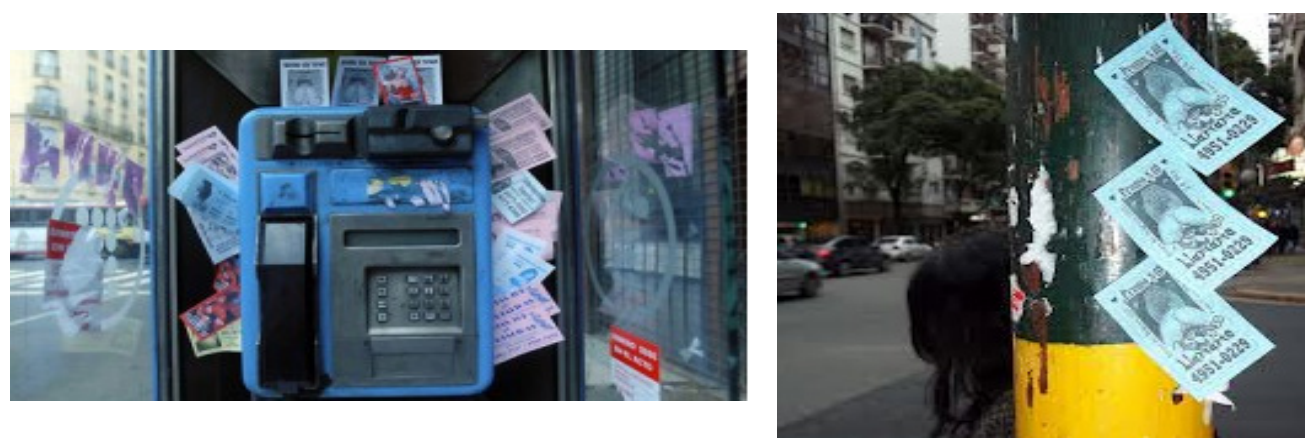

En Argentina, en cambio, dice Chantal Stevens que "el 80 \% de los medios de prensa gráfica han dejado de publicar avisos de oferta de comercio sexual y los que continúan infringiendo la norma (el decreto 936 de 2011) evitan redacciones que confieren un trato denigrante a las mujeres ${ }^{14 "}$. Este resultado, quizá, fue obtenido porque el Decreto goza del respaldo de una política materializada en la Oficina de Monitoreo de publicación de ofertas de comercio sexual. A través de esta oficina se ha obtenido información valiosa (contenida en los avisos) para promover denuncias penales y contribuir con investigaciones judiciales:

13 Ibíd.

14 Stevens Chantal (2013). Investigación proactiva de los delitos de trata de personas y explotación sexual: presentación de un caso denunciado por la Oficina de Monitoreo de publicación de avisos de oferta de comercio sexual del Ministerio de Justicia y derechos humanos de la República argentina, a partir de un volante de promoción sexual de la vía pública. Ponencia presentada en el III Congreso Latinoamericano sobre trata y tráfico de personas. Globalización trata y acceso a la justicia: articulación de diálogos regionales. http://cei.uniandes.edu.co/index.php/recursos/congreso-trata-2013 
[...] permite establecer vínculos entre prostíbulos que funcionan en red, estimar la cantidad de mujeres y niñas que habría en los mismos, establecer si hay migrantes en estos sitios, conocer los días y horarios de funcionamiento, así como las tarifas y porcentajes de comisión retenidos por los explotadores, inferir si hay situaciones de posible regenteo de la prostitución o proxenetismo, estimar los costos fijos de promoción de la actividad, determinar algunos actores que podrían estar implicados en las redes de explotación sexual y trata (por ejemplo los titulares de las líneas telefónicas en los lugares publicitados) y establecer diferentes puntos del país en donde operan las redes de explotación sexual. La información... ha permitido establecer el sistema de plazas mediante el cual las mujeres son trasladadas de un prostíbulo a otro, como también la existencia de situaciones de promoción sexual de mujeres en un idioma distinto al del país en que se encuentran ${ }^{15}$.

Los resultados de la aplicación del Decreto y él en sí mismo permiten nombrar los medios, ya no como intermediarios sino como proxenetas.

En Colombia, en materia de legislación, ha sido el senador Mario Benedetti quien se ha ocupado de incluir en el capítulo VI del proyecto de ley prostitución "Por el cual se establece un trato digno a las personas que se encuentran en situación, condición o estado de prostitución, se fijan medidas afirmativas a su favor y se dictan otras disposiciones orientadas a restablecer sus derechos", la prohibición a los medios de comunicación

[...] televisivos, escritos, radiales, virtuales y páginas web que operan en el territorio colombiano prestar servicios de clasificados, realizar propagandas, presentar programas, concursos u ofrecer servicios donde se haga insinuación explícita o implícita de servicios sexuales y aquellos que guarden relación directa, so pena de ser multados de diez (10) a cien (100) salarios mínimos legales mensuales vigentes por parte del Ministerio de Tecnologías de la Información y las Comunicaciones, y retirados o censurados los actos prohibidos ${ }^{16}$.

Si bien las investigaciones adelantadas en México y Argentina desvelan la necesidad de establecer unos mecanismos de control para regular las acciones desmedidas de quienes se han identificado como corresponsables de la explotación y la trata, es decir, de los medios, también es cierto que reprimir no es suficiente pues la reacción de quienes siguen comprando el espacio a los periódicos para publicar los avisos con contenido sexual en Argentina es la de cambiar el lenguaje de explícito a sugestivo. Recordemos que en México, ante la prohibición, la reacción fue cambiar de periódico/s para seguir con el negocio. De hecho, la prohibición a través de las leyes es el último recurso contra la explotación y la trata.

\section{Teorías funcionalistas y trata de personas ${ }^{17}$}

Pero los medios a través de los cuales se engancha a las personas para su trata y explotación no son únicamente los periódicos. En este punto, resulta interesante y pertinente

15 Ibíd.

16 http://armandobenedetti.com/proyecto/674

17 ¿Qué tipo de metodologías de análisis se utilizan para hacer la interpretación de este fenómeno?, ¿qué resultados han sido obtenidos? 
realizar un análisis funcionalista de la comunicación aplicada al uso de avisos para captar jóvenes para la explotación (aparentemente no solo sexual) y la trata, tomando como base los modelos de Harold Laswell y Paul Lazarfeld para detallar aún más el modus operandi de las redes de explotación y trata:

¿Quién dice?: las agencias de empleo, los intermediarios (dueños de los periódicos y proxenetas), los "sexoprestadores".

¿Qué dice?: se ofrecen empleos "buenos, bonitos y baratos", prestamos de dinero, prestación de servicios sexuales, entre otros.

¿A quién dice?: se dirigen, principalmente, a jóvenes que buscan sus primeros empleos y a clientes potenciales.

¿Por qué canal?: avisos de prensa con y sin contenido sexual, volantes y folletos repartidos en zonas aledañas a las prostíbulos y en las calles o pegados en la vía pública sobre paredes, postes de la luz, teléfonos públicos, canecas para la basura, buses o transporte público e Internet (versión electrónica de los avisos de prensa, páginas web de clasificados gratuitos, redes sociales, blogs, salas de chat y foros de usuarios).

¿Con qué efecto?: obtener ganancias incalculables para algunos de los integrantes de la red pues quienes menos ganancias obtienen son quienes prestan los servicios sexuales, y es precisamente en esto en lo que consiste la explotación.

Hasta hace poco, conocimos la dinámica que utilizan algunas mujeres mayores en Cartagena Colombia para ofrecer sus servicios sexuales. En este caso, ellas hacen uso de sus propios apartamentos y pautan directamente, es decir, no requieren de intermediarios ni proxenetas. Unos años más adelante de Laswell, Paul Lazarfeld propone la observación de los grupos y los líderes que median entre quién dice y a quién se le dice, pues considera que son estos (grupos y líderes) los que dinamizan a la masa, entendiendo por esta última a la mayor cantidad de personas (que responde a la información publicada a través del canal más óptimo en el menor tiempo posible). Patricia Bustamante, del Centro de Capacitación y Servicio para la Mujer, CESACEM, de Bolivia ${ }^{18}$, realiza una caracterización de las actividades que desempeñan los tratantes que admiten la interpretación propuesta desde Lazarfeld. Patricia se refiere a los líderes que conforman el grupo de los tratantes que movilizan la red de trata y explotación y que se esconden detrás de los avisos o de los anuncios (antes o después de que ocurre la captación) haciendo uso del anonimato que les permite publicar información falsa:

18 Centro de Capacitación y Servicio para la Mujer (2013). Los métodos de la trata de personas en Bolivia. Ponencia presentada en el III Congreso Latinoamericano sobre trata y tráfico de personas. Globalización trata y acceso a la justicia: articulación de diálogos regionales. http://cei.uniandes.edu.co/index.php/ recursos/congreso-trata-2013 
Entregadores o enganchadores. Son las personas que descubren y abordan a las víctimas.

Negociadores o intermediarios. Son agentes de enlace entre los entregadores y las casas de prostitución y/o lugares de explotación.

Comisionistas. Son personas que trabajan en oficinas de colocaciones o agencias de empleo y publican avisos ilusorios en los periódicos.

Falsificadores. Proporcionan documentación falsa a las víctimas, generalmente para trasladarlas a otros países.

Indicadores. Se ocupan de vigilar los movimientos de la policía para alertar sobre cualquier operativo o allanamiento.

Comerciantes sexuales. Son los propietarios de casas de prostitución o lenocinios, legales o clandestinos, que comercian con el sexo.

Rufianes o proxenetas. Personas que viven del dinero producto del comercio sexual que realizan una o varias víctimas. Su forma de trabajo consiste en la coerción, el miedo y/o el castigo físico si no cumplen con sus exigencias. De acuerdo a esta tipificación de actividades ilícitas que realizan los tratantes, se puede hablar de una verdadera corporación delictuosa, más aún si se refiere al comercio sexual.
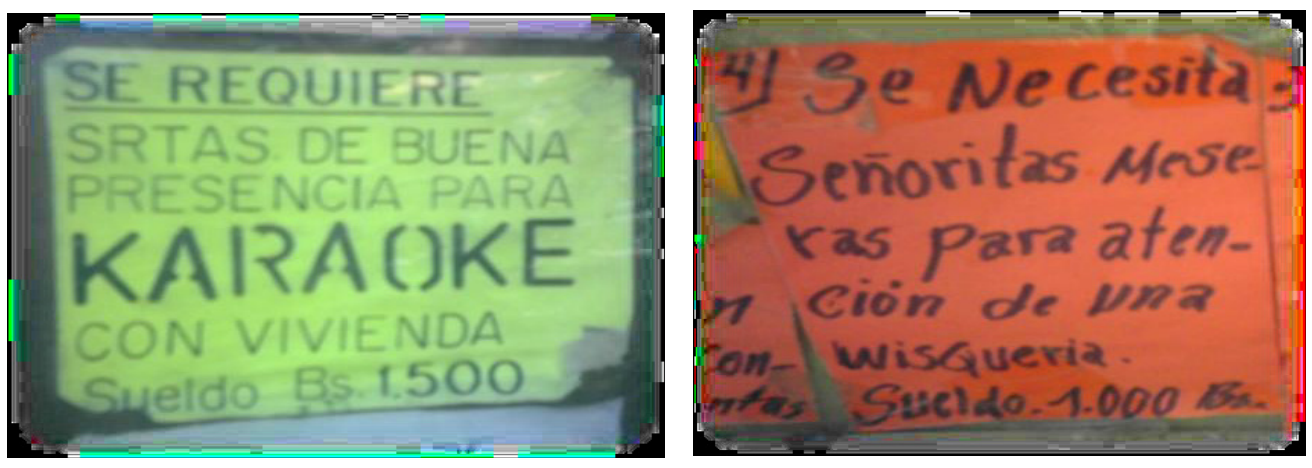

Para explicar "la publicación de información falsa", haré referencia al engaño, una de las principales estrategias utilizadas por los explotadores y los tratantes. Consiste, básicamente, en conocer las condiciones que hacen vulnerable a una persona, en este caso, a los jóvenes para aprovecharse de ellos. Algunos de ellos, quienes finalizan el bachillerato e inician la universidad en un rango de edad entre los 18 y 25 años, se encuentran en una etapa de realización de propósitos vitales, entre ellos los profesionales o laborales. Otros, buscan la independencia a través de la generación de recursos propios y el reconocimiento social que este confiere.

Es por esto que organizaciones como la Red TAMAR ${ }^{19}$ en Colombia buscan hacerle contrapeso a los explotadores y tratantes a través de la prevención. TAMAR ha convertido

19 Tamar es una red internacional conformada por congregaciones de religiosas, organizaciones de la sociedad civil, laicos comprometidos que unidos trabajan por la prevención de la explotación sexual comercial para recuperar la dignificación de las personas. 
en material pedagógico los avisos "anzuelo20", a través de fichas que tienen por "el tiro" la información tomada de los avisos, y por "el retiro", una explicación sobre la modalidad de trata en que puede caer la persona. Como estamos haciendo referencia a jóvenes en condiciones de vulnerabilidad únicamente, citamos a continuación los contenidos de algunas de las fichas:

\section{Prestigiosa agencia de turismo "Caribe Resort".}

Texto tiro: "Se prepara para ofrecer su plan completo de servicios, para una semana espectacular de vacaciones disfrutando de las bellas islas del Caribe. Interesados en trabajar como guías turísticos pueden enviar su hoja de vida, con foto reciente de rostro y cuerpo entero a XXXXX. Requisitos: excelente presentación personal, preferentemente jóvenes o adolescentes entre 13 y 18 años, mujeres o varones. Contrato temporal con posibilidad de ser integrado al personal de planta de la agencia". Texto retiro: "Según la organización mundial de turismo, un $20 \%$ de los 700 millones de viajes que se producen anualmente en el mundo, tiene como principal motivo la explotación de niños, niñas, adolescentes y mujeres. Este mercado clandestino constituye el tercer negocio ilegal más lucrativo, después del tráfico de armas y drogas, produciendo alrededor de 5 mil millones de dólares al año. Fuente: Revista de turismo sexual infantil de la Fundación Red de sanción social contra el abuso sexual infantil, página 9".

\section{“¿Sueñas con ser actor o actriz? Esta es la oportunidad de tu vida.}

Texto tiro: "Producción cinematográfica internacional a filmarse en Panamá, busca actores naturales, mujeres de 16 a 26 años u hombres de 16 a 30 años. Interesados enviar hoja de vida a XXXXX. Anexar foto reciente". Texto retiro: "El año pasado según los datos del DAS-Interpol fueron víctimas de trata externa 155 personas: 146 adultos (mujeres y hombres) y 9 menores. Los tres lugares de destino con más alto porcentaje fueron: Ecuador (33 personas), Trinidad y Tobago (15) y Panamá (11)”.

\section{Solicitud urgente de modelos para trabajar en comerciales de cine y televisión}

Texto tiro: "Preferentemente bachilleres entre 18 y 25 años de edad con excelente presentación personal, talento y hábil desempeño profesional. Nuestra agencia publicitaria es una de las más cotizadas a nivel nacional e internacional. Usted puede acceder a una exitosa carrera de modelaje que le abrirá las pasarelas al mundo. Enviar foto del rostro y de cuerpo entero a XXXXX. La estaremos contactando próximamente para el primer casting". Texto retiro: "La trata de personas es un delito del crimen transnacional organizado y de la trata interna que modifica permanentemente sus modus operandi, especialmente a través del Internet, con fines de explotación sexual, laboral o comercial. En Colombia este delito está penalizado por la Ley 985 de 2005 con de 13 a 23 años de prisión y una multa de 800 a 10000 salarios mínimos legales"

\footnotetext{
$20 \quad$ Llamados así por Patricia Bustamante de CESACEM
} 


\section{Jóvenes masajistas exclusivo Spa, para caballeros}

Texto tiro: Nuestra agencia Silueta Perfecta busca hombres jóvenes entre 18 y 25 años, con amplias expectativas laborales y salariales que atienda la permanente demanda de nuestros clientes en todos los países de América Latina. Contamos con lujosas y confortables instalaciones para ejecutivos y viajeros frecuentes. Ofrecemos altos ingresos según los perfiles de los interesados y contrato de trabajo permanente. Contáctenos: XXXXX. Texto retiro: "la trata de personas en sus diversas modalidades de explotación sexual, laboral y comercial se lucra de la situación de vulnerabilidad de las víctimas, que caen fácilmente en las redes de tratantes para solucionar una difícil situación económica, familiar o social y que no se atreven a denunciar estos delitos por miedo, vergüenza o para evitar retaliaciones contra su vida o la de su familia".

\section{¿Quieres culminar tus estudios de Primaria y Secundaria en Bogotá?}

Texto tiro: "Familia adinerada busca mujer joven (preferentemente menor de edad) para el servicio doméstico. Será acogida, protegida y motivada para que realice sus estudios de Primaria y Secundaria completos, en horarios flexibles con excelente remuneración. Interesadas comunicarse al XXXXX". Texto retiro: "El trabajo servil de menores de edad es más común de lo que puede pensarse. Jóvenes y adolescentes inexpertas, provenientes del área rural son engañadas con este tipo de ofertas. Muchas veces el enlace lo realiza un familiar residente en Bogotá o en algunas ciudades del país a través de la figura de padrinazgo. La víctima se encuentra con que el derecho a estudiar es descontado del sueldo miserable, los horarios flexibles, son las horas de una jornada de trabajo de más de 10 horas y el trato considerado se convierte en un sometimiento forzoso, sin descanso, ni seguridad social, ni garantías legales".

Estas fichas son repartidas en los talleres realizados con niñas, niños y docentes de colegios de Secundaria en todo el país. A partir de ellas se informa a la comunidad educativa y se sensibiliza a los planteles educativos; se proporcionan herramientas de observación para la prevención de este delito en víctimas potenciales para cualquiera de sus modalidades.

En Bolivia, respecto a este tipo de avisos "anzuelo" fue posible, a través de entrevistas realizadas con las víctimas, constatar que los proxenetas y los tratantes ofrecían comisiones a los funcionarios y administradores de agencias de empleo para que facilitaran la llegada de adolescentes y jóvenes especialmente mujeres. De hecho

[...] el 33 \% de los casos relevantes de trata denunciados en la División Trata y Tráfico de personas de El Alto, Cochabamba y Santa Cruz han ocurrido por intermedio de ofrecimientos que se hacen a través de las agencias de empleo; las adolescentes y jovencitas que leen estos anuncios preguntan por los datos de los mismos, entran en contacto con la persona que dejó el anuncio y realizan un acuerdo oral (y en algunos casos escritos -contratos, que son ficticios-), y posteriormente son trasladadas al lugar donde les espera una realidad diferente a lo que esperaban... el $35 \%$ de las menores de edad víctimas de trata y explotación sexual comercial en La Paz y El Alto fueron capta- 
das a través de agencias de empleo, según reza un informe preliminar de Investigación Estadística sobre Trata de Personas en las ciudades de La Paz y El Alto, elaborado por la Organización Internacional para las Migraciones (OIM)... el 40 \% de los casos de las víctimas de trata son traídas del oriente a La Paz... Las muchachas son captadas por una agencia de empleos ubicada en la calle Cañoto en Santa Cruz, con la promesa de recibir buenos ingresos por trabajar como niñeras y vendedoras; las mismas toman interés, hablan con el encargado de la agencia y se les pregunta si están dispuestas a viajar a La Paz. Una vez que reúnen 2 o 3 muchachas, el encargado se comunica con el tratante en La Paz. Desde La Paz, se pagan los pasajes en bus con el nombre y número de carné de identidad de las jóvenes. Las muchachas, al llegar a La Paz, son esperadas en la terminal de buses por una mujer muy amable, que les pide sus documentos para verificar y guardar sus documentos, a fin de que ellas no los pierdan. Al llegar a la casa, luego de descansar y alimentarse, las muchachas observan a otras muchachas, y ya en la noche la mujer les provee de ropa ligera ${ }^{21}$.

El engaño se expresa, como se ha podido constatar en falsas promesas de remuneraciones que superan las ofrecidas por el mercado, de trabajos que no exigen experiencia, ni conocimientos previos, de endeudamientos no calculados por la víctimas cuando los intermediarios ofrecen "casa, carro y beca" y "de gratis como nos gusta" como dicen coloquial y bromistamente en Colombia; falsas promesas que hacen las veces del anzuelo que fácil y "fantasiosamente" "toman por la boca" las personas jóvenes en condiciones de vulnerabilidad. Aunque, bien vale la pena advertir, que hay personas que no caen por un engaño directo sino porque sus condiciones las predisponen y precipitan, las exponen, a la explotación: "La gente sabiendo que en Brasil y Argentina se les explota, igual quiere ir. Vienen otras personas que les dicen, te van a explotar, así igual nomás solicitan viajar. La explotación es algo que no se puede ocultar, todos lo saben. Pero por falta de trabajo se someten; esa es la realidad, no se puede ocultar eso $^{22 " .}$

\section{Teorías estructuralistas y trata de personas}

De acuerdo con las investigaciones revisadas, en Argentina y Colombia, se han hecho esfuerzos por "ver más allá de las imágenes y las palabras, escudriñando entre líneas las significaciones que, a través de los avisos clasificados con contenido sexual, se circulan sobre el cuerpo y el sexo. Retomaré, entonces, los cuatro pasos del método estructuralista general para explicar la presencia del sexismo en las palabras usadas, lo mismo que de la discriminación y exclusión contra las mujeres en las imágenes circuladas."

En Argentina, según Chantal Stevens, se "reproducen estereotipos de género que ponen a las mujeres en situación de subordinación, trato cosificador y discriminatorio 23 ".

$21 \quad$ Centro de Capacitación y Servicio para la Mujer (2013). Los métodos de la trata de personas en Bolivia. Ponencia presentada en el III Congreso Latinoamericano sobre trata y tráfico de personas. Globalización trata y acceso a la justicia: articulación de diálogos regionales. http://cei.uniandes.edu.co/index.php/ recursos/congreso-trata-2013

22 Ibídem

23 Stevens Chantal (2013). Investigación proactiva de los delitos de trata de personas y explotación sexual: presentación de un caso denunciado por la Oficina de Monitoreo de publicación de avisos de oferta de comercio sexual del Ministerio de Justicia y derechos humanos de la República Argentina, a partir de un 
Y en Colombia, según la autora del presente artículo las mujeres y los hombres que protagonizan los avisos con contenido sexual son representados como objetos de consumo a través de los "estereotipos de deseo y placer expresados en la belleza, la juventud, la pureza y el estatus ${ }^{24 "}$.
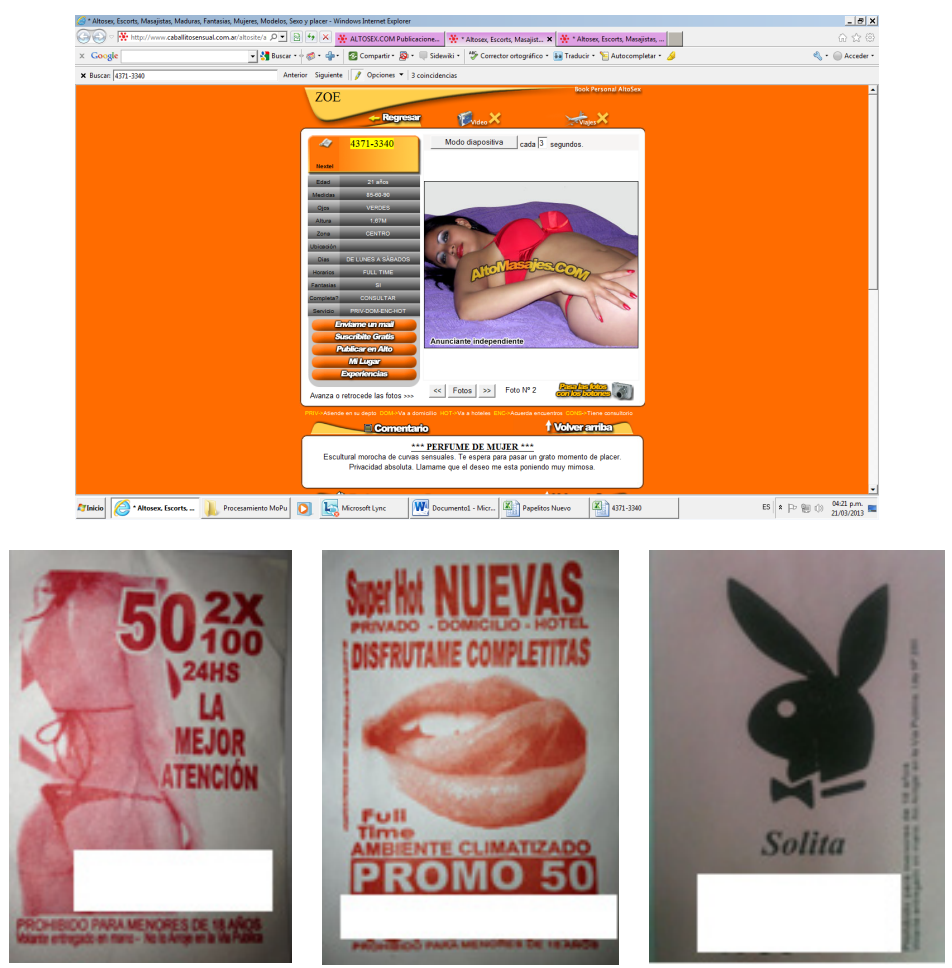

Entre algunas de las conclusiones de las investigaciones adelantadas en Argentina acerca de los "patrones discriminatorios que cosifican a las mujeres" se cuentan:

1. La oferta variada rastreada a partir de lo que con palabras dicen los textos de los canales (medios) analizados, pues estos hablan de "Nuevitas, plantel renovado, nuevo staff, flaquitas y pulposas, traviesa universitaria, señoritas a elección, maduritasbebotas, gatitas completitas...", mejor dicho, para todos los gustos, preferencias y caprichos de consumo.

2. Los textos que alternan voces en primera y tercera personas que permiten concluir quién ofrece el servicio, y

volante de promoción sexual de la vía pública. Ponencia presentada en el III Congreso Latinoamericano sobre trata y tráfico de personas. Globalización trata y acceso a la justicia: articulación de diálogos regionales. http://cei.uniandes.edu.co/index.php/recursos/congreso-trata-2013

24 Castillo Murillejo Norma Constanza (2012). Consumo de mujeres a través de los medios de comunicación: ¿Qué relación tienen la belleza, la juventud, la pureza y el status con la trata de personas?. http://avalon. utadeo.edu.co/comunidades/observatorios/comunicacion/docs/articulo.pdf 
3. Los que dicen 2 xl, que también se ofrecen promociones como se hace con cualquier "otro" objeto.

En Colombia, después de realizar un monitoreo temático de avisos clasificados con contenido sexual publicados en periódicos de circulación regional en zonas de alta vulnerabilidad como Vanguardia Liberal de Bucaramanga y El Heraldo de Barranquilla, así como en periódicos de circulación nacional como El Tiempo y de públicos muy específicos como el Espacio, así como en algunas páginas web, respecto a las formas de nombrar y su relación con los contenidos culturales discriminatorios y excluyentes "vistos" a través de los "lentes de género", se obtuvo el siguiente mapa analítico que habla por sí solo:

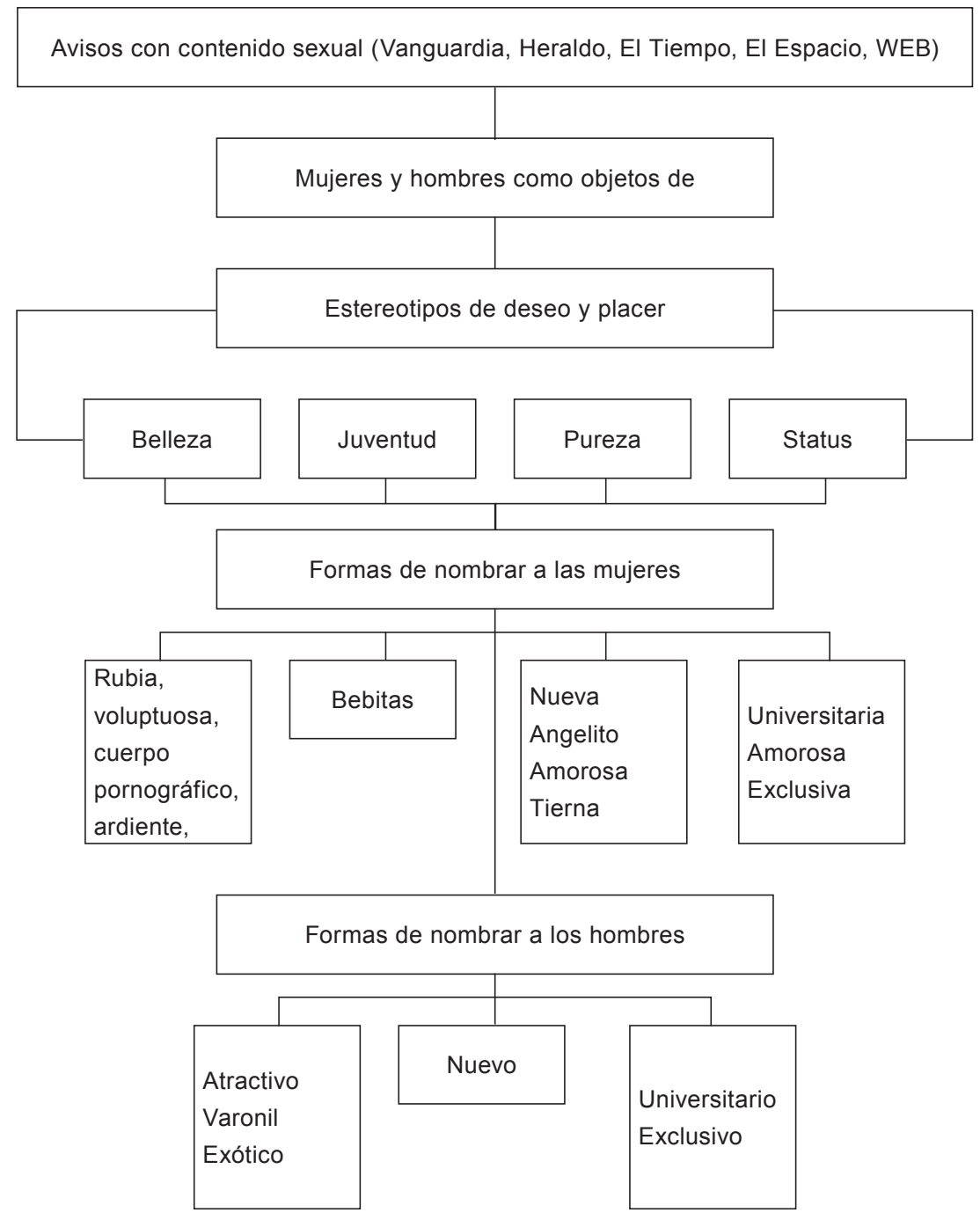


Después de lo dicho resulta pertinente explicar el método y la manera como se cruza con los contenidos encontrados:

Paso N1. Definición del sistema y de sus elementos. El sistema que se encuentra detrás de las formas de nombrar a las mujeres en el mercado de la trata de personas tanto en Colombia como en Argentina es, sin lugar a dudas, el androcentrismo que se define como la práctica de otorgar al punto de vista masculino una posición central en la visión del mundo, de la cultura y de la historia. Esta concepción anula y disminuye el papel de la mujer. En este primer paso y en articulación con los resultados de las investigaciones se puede afirmar que el mercado del sexo está fundamentado en las mujeres y los hombres que respondan a los estereotipos o imágenes universales

Paso N2. El descubrimiento de la estructura. La misma, entendida como un conjunto de sistemas interdependientes que significan desde dicha característica, es el llamado sexismo o trato desigual de las personas en razón a su sexo. En este segundo paso y en articulación con los resultados de las investigaciones se puede afirmar que los patrones de fundamentación del mercado se establecen en una relación asimétrica entre los hombres y las mujeres que ofrecen sexo y quienes lo compran ya que los primeros deben cumplir con los estereotipos consumidos por los segundos porque valen más y generan mayor rentabilidad quienes responden a los estereotipos

Paso N3. Hacer hablar a la estructura. La estructura habla a través del lenguaje sexista entendido como la expresión del androcentrismo a través del lenguaje en forma de sustantivos y en este caso de adjetivos. Todos y cada uno de los adjetivos identificados en los avisos clasificados con contenido sexual hacen uso del lenguaje sexista, afirmación que no hace falta reiterar con los mismos ejemplos.

Pero como la estructura desvelada está dentro de un sistema social a partir del cual se establecen formas de comportamiento atravesadas por las ideas, las creencias y los valores relacionados con el cuerpo y la virginidad, aceptados y establecidos por las instituciones sociales, se hace necesario explicar las bases que dicho sistema tiene en Colombia.

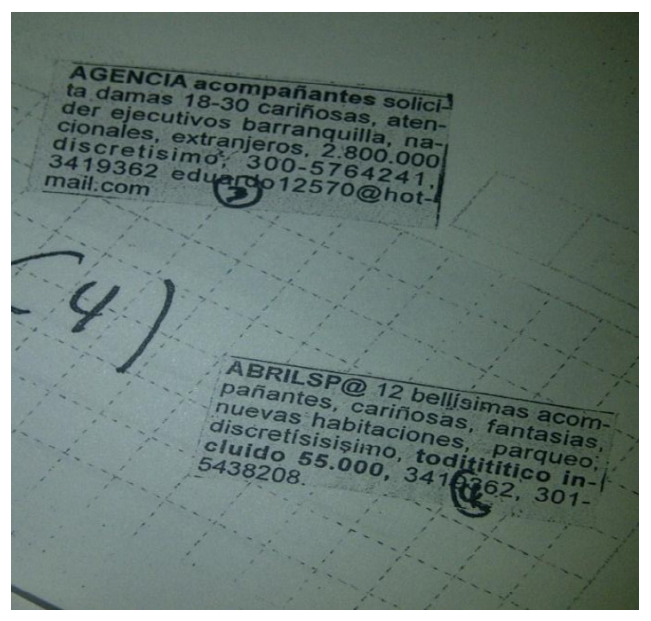


Una de las principales conclusiones de la investigación realizada en Colombia, permite hacer visibles las ideas, las creencias y los valores sobre los que se fundamentan los estereotipos o "conjunto de características comunes y determinantes para un grupo social25" que se originan en el cuerpo, entendido en el contexto de la explotación sexual como el principal medio de comunicación de masas o más efectivo para llegar a la mayor cantidad de personas en el menor tiempo posible: la voluptuosidad, el cuerpo pornográfico, la sensualidad, lo lindo de su cuerpo, su cara de muñeca, su cabello rubio, lo linda, lo hermosa, lo atractiva, lo bellísima y lo ardiente o lo atractivo, lo varonil, lo exótico, lo dotado, lo versátil ${ }^{26}$ que puedan ser una mujer o un hombre, sencillamente funcionan; son "cualidades" funcionales para el negocio. Y el hecho de que sean nuevas, nuevos lo hace más rentable. Una mirada retrospectiva de lo que está vigente en 2013 en el mercado de la trata permite revisar la concepción del cuerpo en el sistema colombiano. Lo que dice esta mirada retrospectiva, en relación con el cuerpo, es que hace 56 años el cuerpo de la mujer (para el sistema religioso, educativo, legal, económico, cultural y social) era otro de los bienes adquiridos por el hombre y la virginidad era el pasaporte para emprender el viaje a lo indisoluble: la unión de una pareja mediante el matrimonio católico ${ }^{27}$. Esto, de acuerdo con los resultados de una investigación realizada en otro contexto, que en mi criterio, admiten comparación. Hoy, en el contexto de la trata de personas, el cuerpo sigue siendo un bien, es decir, una cosa adquirida a través del dinero, y la virginidad, un "valor" que, sin lugar a dudas, aumenta tanto el precio de la mercancía como el "estatus" de la virilidad del consumidor. Uno de los testimonios recuperados por Helga Flamtermesky Coordinadora del proyecto Mujer Frontera (www.mujerfrontera.com) del departamento Psicología Social Universidad Autónoma de Barcelona permite trazar un puente entre el "ayer" y el "ahora:

Testimonio N1- Acerca del uso de la virginidad en el mercado de la explotación sexual y la trata de personas:

Lily se maquilló y se vistió para recibirme. Tenía 20 años cuando la conocí aunque parecía de $15[. .$.$] era una de las chicas que se camuflaba como vendedora de ropa y$ maquillaje en diferentes prostíbulos. Su trabajo era detectar a niñas y mujeres que estuvieran forzadas o que estuvieran a punto de viajar para ser esclavas en otro país. [...]. Cuando tenía cinco años y su hermano seis sus padres empezaron a vender sus servicios y "caricias" para conductores de taxis y buses. Me explicó cómo recordaba el primer día que la obligaron a meterse en la boca el pene de un señor, recordaba el olor, los colores [... .] El trabajo consistía en entrar al coche y metérsela en la boca y salir rápido del coche. Una y otra vez; con diferentes hombres, todo el día. [.. .] No importaba si lloraba; es más, sus padres le decían que si lloraba a los clientes les gustaba más. [...] Su padre vigilaba para que no la tocaran mucho, y vigilaba para que no la violaran. Ante todo tenía que

25 Marco López Paredes. La sociedad frente a los estereotipos" (2009). VII Bienal Iberoamericana de comunicación, Chiguagua México.

26 Claudia Barreto, Estefanía Zapata, Tatiana Moreno, Nahir Mur (2012). Análisis descriptivo de los estereotipos de mujer identificados en los avisos con contenido sexual publicados en El Heraldo, El Espacio, El Tiempo, Páginas WEB. En observatorio de comunicación UJTL

27 Castillo, M. Norma C (2009). ¿Por qué razones distintas a la filiación política nos matábamos los colombianos en los años 50? http://www.javeriana.edu.co/revistas/Facultad/sociales/universitas/www/67.html 
conservar su virginidad para poder venderla después. Cuando le llegó su primera regla empezaron a ofrecer su virginidad en una casa de prostitución. Sus padres la llevaban allí el segundo, tercer, y cuarto día de regla para fingir un sangrado de virginidad y de desgarro. En la casa la escondían de los clientes para poder ser vendida como virgen...

Otro da cuenta de las estrategias que han desarrollado los proxenetas para vender la virginidad una y otra vez.

Testimonio 2- Sobre la virginidad como una farsa:

También me sorprendió que la virginidad se buscara no solo en niñas sino también en mujeres mayores de 20 o 30 años. En la primera visita que hice a un puerto donde hay un centro escondido de rescate, atención y acogida a víctimas de trata vi que en la sala donde comen y se reúnen... había unos carteles con la foto de una fruta y una serie de recomendaciones en varias lenguas. No entendía por qué esa fruta encabezaba advertencias y recomendaciones para mujeres que no estuvieron en situación de trata. Pregunté qué era esa fruta y por qué estaba en el cartel. Las mujeres hicieron silencio y se miraban entre ellas, y le pidieron a la psicóloga del centro que me explicara, porque a ellas les daba vergüenza. El cartel era una advertencia sobre el uso de esa fruta dentro de la vagina de las mujeres, las enfermedades que da, y recomendaciones para lavarse después de usarla. Esa fruta roja, pequeña como una uva se utiliza para vender la virginidad varias veces. Las mujeres con las que hablamos ese día nos contaron que a algunas les obligaban a ponérsela varias veces al día para engañar a clientes pues esa fruta explotaba en su vagina y parecía sangre. Ser vendidas como vírgenes en otros países de Asia implicaba que las estuvieran moviendo frecuentemente, cambiándolas de lugar. Dos de las mujeres con las que hablamos vivieron esto en el Japón y contaban que cuando se enfermaron sus mismos captores las dejaron frente a la embajada de Filipinas para que se declararan víctimas de trata y fueran deportadas. Así se quitaban ellos el problema...

Además del presentado, los resultados de la investigación permiten llegar a otras conclusiones que aparentemente no están relacionadas con el enfoque diferencial de género pero que en realidad sugieren otros campos de investigación:

- Los hombres también son objeto de consumo sexual. Las mujeres también demandan servicios sexuales y en determinadas regiones, ejercen la trata de personas (especialmente aquellas que fueron víctimas del delito y que lograron "ganarse la confianza" de los altos mandos del grupo $)^{28}$.

- Los apelativos de universitaria y universitario proporcionan elementos para ampliar el perfil de las víctimas vulnerables. El perfil de la víctima se define como generalmente mujeres y niños de zonas rurales, barrios marginales, familias desintegradas en búsqueda de mejor nivel de vida y/o extranjeros de minorías étnicas. Pero, entonces: ¿Quiénes son las y los universitarios que se ofrecen en el mercado del sexo?

- $\quad$ El mercado del sexo ofrecido a través de los periódicos contiene mensajes explícitos que aparentemente no recurren al engaño. Las víctimas de trata de personas suelen

28 UNODC (2011) Campaña corazón azul contra la trata de personas. Documento digital. 
ser captadas con métodos fraudulentos y engañosos a través de... anuncios en medios impresos, contactos por internet / chat.

- La venta de sexo y de belleza, a través de los medios de comunicación, es un negocio rentable. La trata de personas es la tercera fuente de ingresos para la delincuencia organizada transnacional y está íntimamente vinculada a otros delitos como el secuestro, la extorsión, el lavado de dinero, la corrupción, el tráfico de drogas y el tráfico ilícito de migrantes por tierra, mar y aire.

En Colombia, antes (en los años 50), una mujer bella, joven y "pura (virgen)" era la depositaria de la herencia de su esposo a través de los hijos que engendrara, en pocas palabras no dejaba de ser un bien más pues no gozaba de su autonomía y poder de decisión sobre su cuerpo y su proyecto de vida. Ahora, en el contexto de la trata de personas, la belleza se asocia con las "cualidades" del cuerpo que en términos estructuralistas (del sistema y de la estructura) encuentra su plenitud en la llamada industria del Fitness promovida por los medios de comunicación y la publicidad que garantizan su permanencia. Como bien ha dicho María Inés Landa en un artículo reciente ${ }^{29}$, el Fitness es una industria alimentada por la estética de la funcionalidad en la que el cuerpo es un "signo de valoración y medición de los sujetos, belleza natural, bienestar emocional, autocontrol, adaptabilidad que se consigue a través de las prácticas corporales realizadas en un gimnasio con la guía y orientación de un profesional"; y del consumo de productos dietéticos, aparatos de gimnasia y gimnasios, música y ropa para hacer ejercicio, tratamientos y en último caso (bueno en ocasiones en primer caso) cirugías estéticas o maquillaje en exceso. La industria del fitness es toda una "pedagogía del cuerpo que vela por la conservación de la masculinidad (Atlas) y la feminidad (Jane Fonda), promovida por las técnicas de marketing..., las televentas" y los avisos clasificados con contenido sexual publicados en prensa impresa, electrónica y páginas web, "lo mismo sucede con las revistas de estilo de vida que exhiben cuerpos atléticos ${ }^{30 "}$.

Ahora, no es solo a través de la prensa escrita, la publicidad o la televisión, sobre las que circulan los estereotipos clásicos y contemporáneos de mujer sino su propio cuerpo: "las mujeres son prácticamente las más afectadas por las comunicaciones ya que están estereotipadas al máximo al punto que todas se podrían encajar en un estereotipo, debido a los comerciales y, más que todo, a la moda que día a día muestra a mujeres extremadamente delgadas, modelo que la sociedad femenina intentará imitar... 31". En la misma línea de Marcos, la investigación concluye que todos los anuncios estudiados se ubican en las páginas de avisos clasificados, es decir, en la sección comercial aquella que, junto a la pauta publicitaria, garantiza la supervivencia de los periódicos.

Me pregunto entonces: el hecho de que seamos "iguales (estereotípicos)" ¿se convierte

29 Landa María Inés Subjetividades y consumos corporales: un análisis de las prácticas del fitness en España y Argentina. www.razonypalabra.org.mx

30

ídem

31 Marco López Paredes. La sociedad frente a los estereotipos" (2009). VII Bienal Iberoamericana de comunicación, Chiguagua México 
en una razón para la compra y para la venta de personas dentro y fuera de la prostitución, en el mercado del sexo? La pregunta queda abierta a la respuesta que usted como lector le quiera dar. Lo único cierto es que en coincidencia con la investigación de Chantal Stevens en los avisos clasificados citados, leídos desde la relación entre mercancía y comprador, predomina el estereotipo explícito de la mujer objeto, tierna, sumisa, de menor desarrollo intelectual y por supuesto siempre bella. Y el estereotipo implícito de hombre dominador (que debe ser complacido), amante del riesgo (compra sexo de mujeres complacientes), el que manda (el que provee el dinero a la mercancía) y el ejecutivo (tiene estatus y demanda estatus: universitarias, educadas). La relación entre mercancía y consumidor comienza a ser directa porque a ellas se las muestra como un objeto y, a ellos, como los dueños de ese objeto o del mundo incluso. Y que como estamos hablando de que "lo que se hereda no se hurta", entonces debo decir que comparto la idea de Marco López cuando dice que el establecimiento de estereotipos en una sociedad comienza con los niños y las niñas y sigue con los jóvenes o si no ¿por qué los niños son presentados por la publicidad (y en algunos de los avisos analizados) como traviesos, irresponsables, despreocupados (versátil), las niñas como obedientes que aceptan las reglas (complacientes) y los jóvenes como atractivos (bellos, bellas)?

Concluyo afirmando que estas formas de actuar de acuerdo con lo que otros esperan de nosotras y de nosotros, que dejan una ganancia y un éxito "aparentes" y grandes cantidades de dinero para los dueños del negocio, se traducen en formas de violencia contra las mujeres y los hombres que se ven representados en las formas de nombrar, de ilustrar y de actuar, aunque los estereotipos (trasmitidos a través de los medios que aparentemente no informan) no son reales sino el resultado de una fragmentación de la mujer, a través de la cual siempre resultamos perdedoras.

Veamos la relación que establezco en el siguiente cuadro entre el cine y los avisos clasificados con contenido sexual:

\begin{tabular}{|l|l|l|}
\hline $\begin{array}{l}\text { Recuento histórico y selectivo de las } \\
\text { representaciones sociales de la mujer } \\
\text { en el cine }\end{array}$ & $\begin{array}{l}\text { Estereotipos de género localiza- } \\
\text { dos en avisos clasificados con } \\
\text { contenido sexual 2012 }\end{array}$ & $\begin{array}{l}\text { Relación de inferiori- } \\
\text { dad de la mujer respec- } \\
\text { to al hombre }\end{array}$ \\
\hline $\begin{array}{l}\text { 1920. Mujer objeto o adorno dentro } \\
\text { del espacio doméstico supeditado a } \\
\text { los deseos del hombre: en la cocina, } \\
\text { dedicada al cuidado de su esposo } \\
\text { e hijos }\end{array}$ & Exclusiva & $\begin{array}{l}\text { En función de los } \\
\text { hombres }\end{array}$ \\
\hline 1930. Mujer objeto de deseo & $\begin{array}{l}\text { Rubia, voluptuosa, cuerpo por } \\
\text { nográfico, ardiente, seductora, } \\
\text { sensual, modelo }\end{array}$ & $\begin{array}{l}\text { En función de los } \\
\text { hombres }\end{array}$ \\
\hline
\end{tabular}

$32 \quad$ Puebla Martínez Belén (2011). La mujer en el cine de Alejandro Amenábar: pinceladas de una nueva feminidad en el cine español. www.razonypalabra.org.mx 


\begin{tabular}{|l|l|l|}
\hline $\begin{array}{l}\text { 1940 1950. Mujer dulce e inocente, } \\
\text { virgen y madre que vive por y para su } \\
\text { marido, cuida del héroe y que destaca } \\
\text { por la ausencia de agresividad sexual }\end{array}$ & $\begin{array}{l}\text { Nueva, angelitos, amorosas, } \\
\text { tiernas }\end{array}$ & $\begin{array}{l}\text { En función de los hom- } \\
\text { bres }\end{array}$ \\
\hline $\begin{array}{l}\text { Prehistoria matriarcal. Mujer activa } \\
\text { y amazónica, terribles guerreras que } \\
\text { devoraban a sus amantes y ene- } \\
\text { migos; en este sentido las mujeres } \\
\text { son responsables de los males de la } \\
\text { humanidad }\end{array}$ & Prostituta & $\begin{array}{l}\text { Siempre perdedora, } \\
\text { para los hombres y las } \\
\text { mujeres de mentalidad } \\
\text { patriarcal }\end{array}$ \\
\hline $\begin{array}{l}\text { 2001. Mujer Tomb Raider que piensay y } \\
\text { actuá como un hombre en un mundo } \\
\text { de hombres }\end{array}$ & $\begin{array}{l}\text { Descomplicada y de mente } \\
\text { abierta }\end{array}$ & $\begin{array}{l}\text { Siempre perdedora } \\
\text { para los hombres y las } \\
\text { mujeres de mentalidad } \\
\text { patriarcal }\end{array}$ \\
\hline
\end{tabular}

Los resultados descritos y analizados en Colombia (a excepción de los presentados por la Red TAMAR) hacen parte de la investigación formativa adelantada en la modalidad de proyecto de aula durante el primer semestre de 2012, desde la asignatura Comunicación de masas ofrecida por la Facultad de Comunicación Social-Periodismo de la Universidad Jorge Tadeo Lozano y contribuyen, en términos de Prevención, a la "advertencia de los peligros de la prostitución y el mejoramiento de la educación para reducir la demanda ${ }^{33}$ ", desde la Participación activa de la academia a través del análisis descriptivo y correlacional de los estereotipos de género hegemónicos de la industria cultural del fitness y los medios de comunicación de masas identificados en los avisos clasificados con contenido sexual publicados en Vanguardia Liberal de Bucaramanga, El Heraldo de Barranquilla, El Tiempo y el Espacio de circulación nacional.

\section{Conclusiones}

Lo medios de comunicación deben asumir el reto de informar desde la responsabilidad social que les compete y de considerar todo aquello que se publica como información. Excluir los avisos clasificados de la misión periodística de perseguir la verdad y ofrecer una visión plurifuentista de la realidad para que los receptores saquen sus propias conclusiones no es la forma de participar en la lucha en contra de la explotación sexual y trata de personas en cualquiera de sus modalidades.

La voluntad de hacer el cambio no es suficiente; hace falta capacitarse para "poder ver lo que otros no ven" y liderar la formulación de políticas públicas y la inclusión de acciones propositivas que pueden ejercitarse en el día a día de la redacción de notas 33 The Protection Project y Ricky Martin Foundation (2007) aproximaciones legales para combatir la trata de
personas: una perspectiva internacional comparada 
periodísticas y en el monitoreo (automonitoreo) de aquello que se hace público y que tiene repercusiones serias sobre la vida de las personas en términos de lo que representan para su reconocimiento social.

El reto es integral, y convoca no solo a la academia, las organizaciones gubernamentales y el Estado sino a los medios de comunicación incluyendo a la publicidad y el cine que, aunque aparentemente no ofrezcan información, participan de la construcción de un imaginario social que se fortalece a través de la masificación.

Para finalizar debo decir que aspiro haber dejado en claro: cuál es la relación entre avisos clasificados y trata de personas, quienes usan y para qué usan los avisos clasificados con y sin contenido sexual, dónde se originan las investigaciones y qué sentido tiene realizarlas, qué tipo de metodologías de análisis se utilizan para hacer la interpretación de este fenómeno y qué resultados han sido obtenidos.

\section{Referencias bibliográficas}

Andrés del Campo, Susana (2002) Estereotipos de género en la publicidad de la segunda República española. Madrid, Universidad Complutense de Madrid

Badinter, Elisabeth (1993) XY: la identidad masculina. Bogotá, Grupo Editorial Norma.

Barros Freitas, Lucia. (2004) Discriminación sexista y otras formas de violencia estructural e institucional contra la mujer. Madrid, Universidad Carlos III de Madrid

Butler, Judith (2010) Deshacer el género. Barcelona, Paidós

Butler, Judith, (2010) El género en disputa: el feminismo y la subversión de la identidad. Barcelona, Paidós

Castillo Murillejo Norma Constanza (2012). Consumo de mujeres a través de los medios de comunicación: ¿Qué relación tienen la belleza, la juventud, la pureza y el status con la trata de personas?. http://avalon.utadeo.edu.co/comunidades/observatorios/comunicacion/docs/articulo.pdf

Claudia Barreto, Estefanía Zapata, Tatiana Moreno, Nahir Mur (2012). Análisis descriptivo de los estereotipos de mujer identificados en los avisos con contenido sexual publicados en El Heraldo, El Espacio, El Tiempo, Páginas WEB. En observatorio de comunicación UJTL

Centro de Capacitación y Servicio para la Mujer (2013). Los métodos de la trata de personas en Bolivia. Ponencia presentada en el III Congreso Latinoamericano sobre trata y tráfico de personas. Globalización trata y acceso a la justicia: articulación de diálogos regionales. http://cei.uniandes. edu.co/index.php/recursos/congreso-trata-2013

Cossette Guadarrama Alma (2013). Los Menores Migrantes como Víctimas de la Trata de Personas en la Legislación Mexicana y Dra. Muñoz Cano Skidmore Ma. Dolores y Lic. Granados Cervantes Montcerrat (2013). Trata de niñas y niños con fines de explotación laboral. Ponencia presentada en el III Congreso Latinoamericano sobre trata y tráfico de personas. Globalización trata y acceso a la justicia: articulación de diálogos regionales. http://cei.uniandes.edu.co/index.php/ recursos/congreso-trata-2013

Espinosa Pérez, Beatriz (2008) Cuerpos y diversidad sexual: aportes para la igualdad y el reconocimiento 2008. Bogotá, Pontificia Universidad Javeriana

Fuentes Mario Luis y Arellano Saúl (2012). Los anuncios de servicios sexuales en la prensa escrita 
mexicana. Un análisis exploratorio en los periódicos El Universal, El Gráfico, Metro, Reforma y La Prensa. CEIDAS. Cátedra extraordinaria Trata de personas. Universidad Autónoma de México. http://investigacion.politicas.unam.mx/catedratrata/?page_ id=591

Grima José Manuel. "Trata de personas y derechos humanos". Ponencia central. En: Primer Encuentro Nacional sobre trata de personas. Vínculos para la acción colectiva: sociedad civil, gobierno y academia. Noviembre 6 y 7 de 2012. Bucaramanga, Colombia

http://www.secretariasenado.gov.co/senado/basedoc/ley/2005/ley _ 0985 _ 2005.html

http://armandobenedetti.com/proyecto/674

Marco López Paredes. La sociedad frente a los estereotipos" (2009). VII Bienal Iberoamericana de comunicación, Chiguagua México.

Pearson, Judy C. (1993) Comunicación y género. Barcelona, Ediciones Paidós

Landa María Inés Subjetividades y consumos corporales: un análisis de las prácticas del fitness en España y Argentina. www.razonypalabra.org.mx

Pineda Duque, Javier Armando (c2003) Masculinidades, género y desarrollo: sociedad civil, machismo. Bogotá, Ediciones Uniandes, Facultad de Derecho

Puebla Martínez Belén (2011). La mujer en el cine de Alejandro Amenábar: pinceladas de una nueva feminidad en el cine español. www.razonypalabra.org.mx

Stevens Chantal (2013). Investigación proactiva de los delitos de trata de personas y explotación sexual: presentación de un caso denunciado por la Oficina de Monitoreo de publicación de avisos de oferta de comercio sexual del Ministerio de Justicia y derechos humanos de la República argentina, a partir de un volante de promoción sexual de la vía pública. Ponencia presentada en el III Congreso Latinoamericano sobre trata y tráfico de personas. Globalización trata y acceso a la justicia: articulación de diálogos regionales. http://cei.uniandes.edu.co/index.php/recursos/ congreso-trata-2013

Tamarit Vallés, Inmaculada (2003) Representaciones de la mujer española en el imaginario francés del siglo XVIII. Universidad de Valencia - Facultad de Filología

The Protection Project y Ricky Martin Foundation (2007) aproximaciones legales para combatir la trata de personas: una perspectiva internacional comparada

Rojas Rojas, Claudia Patricia (1989) La mujer en la televisión comercial. UJTL

UNODC (2011) Campaña corazón azul contra la trata de personas. Documento digital.

White, Douglas R (2005). Teoría de la cohesión circular en el matrimonio y las redes sociales. EMPIRIA. Revista de Metodología de las Ciencias Sociales, num 10, jluio-diciembre, 205, p.p. 37-69. Facultad de Ciencias Políticas y sociología, Madrid, España. http://www.redalyc.org/ pdf/2971/297123998002.pdf

Women's Lin Worldwide (2013). La trata de personas en Colombia: país de origen, tránsito y destino de víctimas de trata transnacional e interna. Ponencia presentada en el III Congreso Latinoamericano sobre trata y tráfico de personas. Globalización trata y acceso a la justicia: articulación de diálogos regionales. http://cei.uniandes.edu.co/index.php/recursos/congreso-trata-2013 